\title{
LETTER
}

\section{Laser Raman spectroscopic measurements of water in unexposed glass inclusions}

\author{
Rainer Thomas, ${ }^{1, *}$ VAdim S. Kamenetsky, ${ }^{2}$ and Paul Davidson ${ }^{2}$
}

${ }^{1}$ GeoForschungsZentrum Potsdam, Division 4, Telegrafenberg, 14473 Potsdam, Germany

${ }^{2}$ ARC Centre of Excellence in Ore Deposits, University of Tasmania, Hobart 7001, Australia

\begin{abstract}
A method is proposed for determining the water concentration in silicate melt inclusions (MI) by confocal micro-Raman spectroscopy, without exposing the inclusions for measurement (a prerequisite of all previous methods). The latter is important for extremely water-rich MI (e.g., those in evolved granites and pegmatites), which would loose $\mathrm{H}_{2} \mathrm{O}$ on exposure. Furthermore, this technique permits determination of the water concentration in a single MI. We use a comparative technique, determining the total water content of a sample against a reference glass of known water content. Because this process is non-destructive it does not preclude the subsequent use of other analytical techniques.

Keywords: Raman spectroscopy, water determination, unexposed silicate melt inclusions, water in glasses
\end{abstract}

\section{INTRODUCTION}

The determination of water in silicate glasses of different compositions, using confocal micro-Raman spectroscopy, is now a well-established routine method (Chabiron et al. 2004; Di Muro et al. 2006; Thomas 2000, 2002; Thomas et al. 2000, 2003, 2005). This technique can be used for an accurate and fast analysis of total dissolved water $\left(\mathrm{H}_{2} \mathrm{O}_{\mathrm{T}}\right)$ even in small volume $\left(<10 \mu \mathrm{m}^{3}\right)$ melt inclusions (MI). The same technique can determine $\mathrm{D}_{2} \mathrm{O}$, provided the $\mathrm{D}_{2} \mathrm{O}-\mathrm{OD}$ spectra are taken in the frequency range $2250-2900 \mathrm{~cm}^{-1}$ with the band maxima at 2608 and $2656 \mathrm{~cm}^{-1}$. Previous methods involved focusing the laser beam on MI exposed by polishing; however, Chabiron et al. (2004) have shown that better results can be achieved if the inclusions are at a depth of $\sim 15 \mu \mathrm{m}$ below the surface. According to Thomas (2000) and Di Muro et al. (2006) the optimal depth depends primarily on the confocal performance, and is about $2 \mu \mathrm{m}$ for the Dilor XY spectrometer used in this study. Besides the quantification of water, Di Muro et al. (2006) have shown that the water speciation $\left(\mathrm{H}_{2} \mathrm{O}_{\mathrm{m}} / \mathrm{OH}\right)$ can also be determined successfully by confocal micro-Raman spectroscopic analysis.

During our analytical work on MI from different rocks we observed apparent water-loss during secondary ion mass spectrometry (SIMS), or electron microprobe analyses (EMPA) taken prior to Raman analyses, a feature also observed by Di Muro et al. (2005), Leschik et al. (2004) and Humphreys (personal communication). At high water concentrations in the glass $(>8-10$ wt $\%$ ) we also observed $\mathrm{H}_{2} \mathrm{O}$-loss with time, possibly caused by changes in the glass related to polishing, and also by diffusion effects during local heating by the laser. Leschik et al. (2004) have shown that $\mathrm{H}_{2} \mathrm{O}$ is released under vacuum, at room temperature, from glasses containing $>7 \mathrm{wt} \% \mathrm{H}_{2} \mathrm{O}$. Determination of water content in unexposed glass inclusions would eliminate these sources of error. Such a technique also would make it possible to determine high water concentrations in MI (>20 wt \%),

*E-mail: thomas@gfz-potsdam.de which is at the present time impossible with FTIR, EMPA, or SIMS. A solution to this problem, outlined briefly in Thomas (2000), is described in detail in the present study. Being a nondestructive method, once $\mathrm{H}_{2} \mathrm{O}$ analysis has been performed the inclusions are still available for further analysis. For example, the MI can be exposed to allow analysis of major and trace element compositions.

\section{ANALYTICAL TECHNIQUE AND SAMPLE CHARACTERISTICS}

Total water concentration $\left(\mathrm{H}_{2} \mathrm{O}_{\mathrm{T}}\right)$ was measured using a Raman probe consisting of a Dilor XY Laser Raman Triple $800 \mathrm{~mm}$ spectrometer (1800 G/mm gratings), equipped with an Olympus optical microscope, and a long working distance $80 \times$ objective (required for imaging deep inclusions). The spectral resolution of the system is less than $1 \mathrm{~cm}^{-1}$ in the high resolution mode. Spectra of the MI glasses were collected with a Peltier cooled CCD detector. The 488-nm line of a Coherent $\mathrm{Ar}^{+}$Laser Model Innova 70-3 at $450 \mathrm{~mW}$ was used for sample excitation (corresponding to $36 \mathrm{~mW}$ on sample). For all measurements a confocal pinhole of 150 $\mu \mathrm{m}$ was used (see Thomas 2002). All spectra were measured in the high-frequency range between 2800 and $3980 \mathrm{~cm}^{-1}$ (Fig. 1). For simplicity we have adopted a linear background correction in the integration limits between 3100 and $3750 \mathrm{~cm}^{-1}$ (see

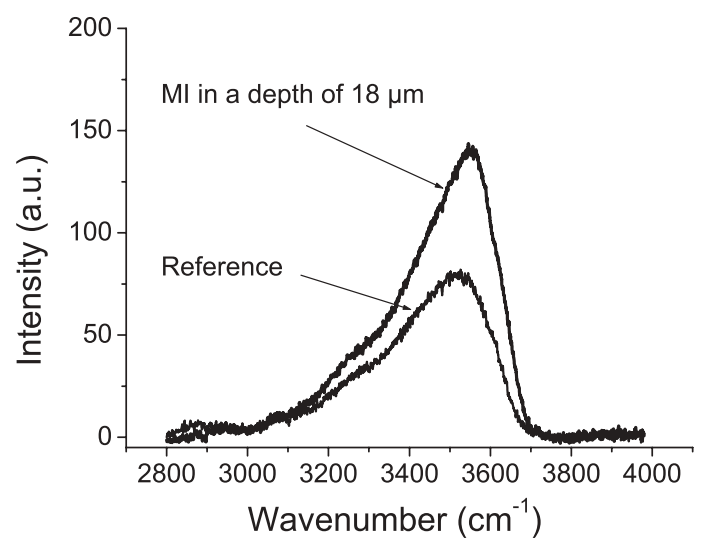

FigURE 1. Unpolarized Raman spectra at the high frequency region taken from a water-rich MI-glass in pegmatite quartz from Ehrenfriedersdorf, and the reference albite glass (AB83) with a total water concentration $\mathrm{H}_{2} \mathrm{O}_{\mathrm{T}}$ of $11.71 \mathrm{wt} \%$ for comparison. 
Ohlhorst et al. 2001)

To avoid excessive influence of the composition-dependent aluminosilicate network-TOT1 bands (see Di Muro et al. 2006) at $490 \mathrm{~cm}^{-1}$, we have used the external calibration method of Di Muro et al. (2006). Thomas (2000) demonstrated the validity of this technique, and the strength of the method is illustrated in Figure 2 , which shows good correlation of the measured integral intensity vs. the water content of synthetic albite, granite and basalt glasses, determined by the Karl Fischer titration (see Table 1). From this data (using only the reference glasses) we obtain a correlation coefficient $r^{2}=0.9962$.

A similarly good linear correlation was also obtained for the $\mathrm{D}_{2} \mathrm{O}_{\mathrm{T}}$ determination in rhyolitic glasses, kindly provided by $\mathrm{M}$. Leschik with $\mathrm{D}_{2} \mathrm{O}$ concentrations between 0.6 and $5.6 \mathrm{wt} \%$ (Fig. 2). We used 5 reference glasses (S99) with 0.69 , $1.02,2.03,3.4$, and $5.6 \mathrm{wt} \% \mathrm{D}_{2} \mathrm{O}$ (see Leschik et al. 2004).

Because the integral intensity of the $\mathrm{H}_{2} \mathrm{O}-\mathrm{OH}$ stretching band increases directly, proportionally and linearly with the total water content (see Thomas 2000), we have used a simple procedure for quantification. The water concentration was calculated from the geometric proportion between the integral intensity of a reference glass (with a $\mathrm{H}_{2} \mathrm{O}_{\mathrm{T}}$ concentration near that of the unknown sample) and the unknown sample intensity. For calibration we used well-characterized standard glasses given in Thomas (2000). This procedure dramatically simplifies quantification because a calibration curve is not necessary. At the same time the compositional dependence is strongly decreased, as we take only the $\mathrm{H}_{2} \mathrm{O}-\mathrm{OH}$ stretching band in the frequency region between 2800 and $3980 \mathrm{~cm}^{-1}$. Three windows are necessary to take the complete spectra (because of the high resolution of the XY spectrometer, grading 1800 groves $/ \mathrm{mm}$ ), and these windows were automatically combined by the software. The acquisition time was $5 \times 50$ s for each window, and the complete measurement time for one spectrum is $750 \mathrm{~s}$.

Laser intensity was checked against the reference glass before each measuring step. The depth of the MI was determined by a calibrated microscope scale (corrected for the refractive index of the inclusion host mineral). The technique is currently restricted to non-opaque minerals. The laser beam was focused on the top of the inclusion, and then lowered by $2 \mu \mathrm{m}$ before measurement began. The confocal beam produces signal from a volume of sample with an approximately inverted conical shape, $2 \mu \mathrm{m}$ wide and $10 \mu \mathrm{m}$ deep, which needs to be taken into account for inclusions less than $10 \mu \mathrm{m}$ thick. To maintain computational consistency, only inclusions with the same thickness (and preferably size) should be used for small inclusions $(\leq 10 \mu \mathrm{m})$.

To test the proposed method we have determined the water content of three different samples: (1) a MI of granitic composition in quartz from the topaz-albite granite, Zinnwald Eastern Erzgebirge, Germany (see Thomas et al. 2005), (2) a water-rich MI with evolved granitic composition in quartz from the Ehrenfriedersdorf pegmatite, Central Erzgebirge, Germany (Thomas et al. 2003), and (3) MI in olivine from Etna volcano, Italy. The Etnean MI are represented by primitive (6-9 wt\% MgO) basaltic glass; host olivine is $\mathrm{Fo}_{90}$

In the case of Zinnwald and Ehrenfriedersdorf, we studied one large MI in

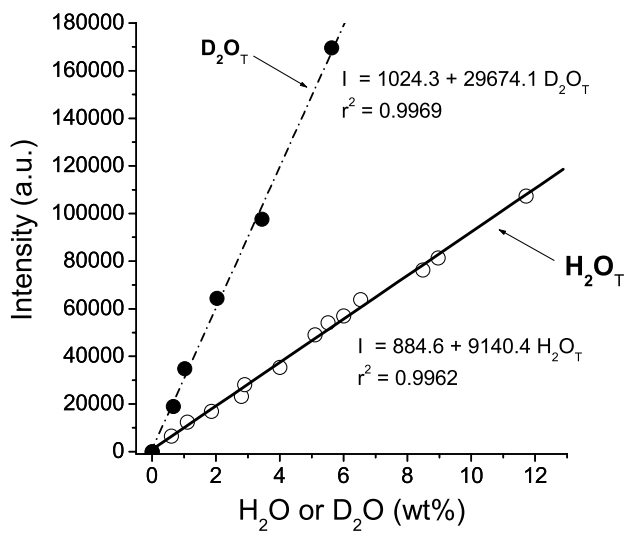

Figure 2. Correlation between $\mathrm{H}_{2} \mathrm{O}$ and $\mathrm{D}_{2} \mathrm{O}$ concentrations in synthetic glasses and the integral intensity between 3100 and $3750 \mathrm{~cm}^{-1}$ and 2250 and $2900 \mathrm{~cm}^{-1}$, respectively. The $\mathrm{H}_{2} \mathrm{O}$ and $\mathrm{D}_{2} \mathrm{O}$ concentrations (in wt $\%$ ) in the synthetic glasses used were determined by Karl Fischer titration. Conditions: $450 \mathrm{~mW}$ laser power, acquisition time $5 \times 50 \mathrm{~s}$, original data for $\mathrm{H}_{2} \mathrm{O}_{\mathrm{T}}$ from Table 1
TABLE 1. Raman spectrometric analyses of $\mathrm{H}_{2} \mathrm{O}_{T}$ and $\mathrm{D}_{2} \mathrm{O}_{\mathrm{T}}$ in different synthetic glasses and natural silicate melt inclusions

\begin{tabular}{|c|c|c|c|}
\hline Glass & $\begin{array}{l}\mathrm{H}_{2} \mathrm{O}_{\mathrm{T}}{ }^{*} \\
(\mathrm{wt} \%)\end{array}$ & $\begin{array}{l}\text { Integral intensity } \\
\left(3100-3750 \mathrm{~cm}^{-1}\right)\end{array}$ & $\begin{array}{l}\text { SD }+ \text { of the Integral } \\
\text { intensity }(1 \sigma)\end{array}$ \\
\hline Dry glass & 0 & 0 & \\
\hline Albite (Behrens) & 0.60 & 6559 & 400 \\
\hline \multicolumn{4}{|l|}{ ANSI 96-11C } \\
\hline (Webster et al. 1999) & $1.10 \neq$ & 12329 & 497 \\
\hline AOQ (Holtz) & 1.86 & 16985 & 2457 \\
\hline Albite (Behrens) & 2.80 & 23158 & \\
\hline Albite (Behrens) & 2.90 & 28110 & 2432 \\
\hline P2 Granite (Holtz) & 4.00 & 35434 & \\
\hline M6N (Westrich) & 5.11 & 49026 & 3510 \\
\hline Albite (Bodnar) & 5.51 & 54168 & \\
\hline \multicolumn{4}{|l|}{ ANSI 97-5E } \\
\hline (Webster et al. 1999) & $6.00 \neq$ & 56994 & 1000 \\
\hline Granite (Behrens) & 6.53 & 63905 & \\
\hline Albite (Bodnar) & 8.48 & 76273 & 2223 \\
\hline Granite (Behrens) & 8.96 & 81300 & 1616 \\
\hline AB83 (Behrens) & 11.71 & 107388 & 4638 \\
\hline Etna-MIs & 4.40 & 40333 & 2795 \\
\hline ZW-MI & 8.90 & 83044 & 1816 \\
\hline \multirow[t]{2}{*}{ Qu8-MI ${ }^{\S}$} & 25.3 & 230043 & 13279 \\
\hline & $\begin{array}{l}\mathrm{D}_{2} \mathrm{O}_{\mathrm{T}}^{*} \\
(\mathrm{wt} \%)\end{array}$ & $\begin{array}{l}\text { Integral intensity } \\
\left(2250-2900 \mathrm{~cm}^{-1}\right)\end{array}$ & \\
\hline D0.5 & 0.69 & 18975 & 812 \\
\hline D1 & 1.02 & 34833 & 1002 \\
\hline D2 & 2.03 & 64346 & 400 \\
\hline D4 & 3.44 & 97579 & 100 \\
\hline D6 & 5.62 & 169648 & 3052 \\
\hline
\end{tabular}

Notes: Data from glasses given by Behrens, Bodnar, Holz, and Westrich are unpublished.

* The $\mathrm{H}_{2} \mathrm{O}$ and $\mathrm{D}_{2} \mathrm{O}$ contents of the reference samples were determined by Kar Fischer titration.

+ SD - standard deviation, obtained from 5 measurements; without SD: only 1 measurement was performed.

\# The water content of the basaltic glass (ANSI samples) was determined by SIMS (1 $\sigma$ ranges from 0.2 to 0.4 ).

$\S$ Melt inclusions in the studied samples from Etna volcano (Etna-MI), Zinnwald granite (ZW-MI), and Ehrenfriedersdorf pegmatite (Qu8-MI).

quartz from each sample. We began analysis with both inclusions at a depth of 72 $\mu \mathrm{m}$ below the surface, then re-ground, re-polished and re-analyzed six times in stepwise fashion, until the inclusion was finally exposed. The Raman signal attenuates proportionately with distance from the inclusion to the surface, dependent on the properties of the host mineral, and we use this signal attenuation in determining the water concentration.

Another strategy was used in the case of MI in olivine from Etna; we selected roughly similar sized, large MI at different depths of the sample, and analyzed these without re-polishing, the assumption being that the different inclusions all have the same $\mathrm{H}_{2} \mathrm{O}$ concentration. In general, as the depth of an inclusion from the surface increases, the counting time must also be increased. However, a measurable Raman signal can still be obtained from a depth of $142 \mu \mathrm{m}$.

The two methods are in a sense analogous, either use one inclusion and bring it to the surface by step-wise polishing and re-analyzing, or choose multiple similar inclusions at different depths, and avoid the need for extra sample preparation.

\section{RESULTS AND DISCUSSION}

Table 2a gives the results of the Raman spectrometric determination of the water content in a single MI in a quartz crystal from the topaz-albite granite from Zinnwald, Eastern-Erzgebirge, Germany. Before measurement, the MI was homogenized in a cold-sealed pressure vessel $\left(700{ }^{\circ} \mathrm{C}\right.$ and $1 \mathrm{kbar}$, pressurized with $\mathrm{CO}_{2}$ for $20 \mathrm{~h}$ ), as $\mathrm{MI}$ from a plutonic environment are generally completely crystallized. The MI (diameter $60 \mu \mathrm{m}$ ) was initially $72 \mu \mathrm{m}$ below the top surface of a double-polished wafer, and was progressively brought to the surface by step-wise grinding and polishing. As an external reference standard, for all mea- 
TABLE 2. Determination of the total water content in silicate melt inclusions

\begin{tabular}{|c|c|c|c|}
\hline$\overline{\text { Depth }(\mu \mathrm{m})^{*}}$ & Integral intensity & $\begin{array}{c}\text { Integral } \\
\text { intensity (\%)† }\end{array}$ & $\begin{array}{l}\mathrm{H}_{2} \mathrm{O} \text {-measured } \\
(w \mathrm{w} \%)\end{array}$ \\
\hline \multicolumn{4}{|c|}{$\begin{array}{c}\mathrm{a}=\mathrm{MI} \text { in quartz from a topaz-albite granite from Zinnwald, E-Erzgebirge, } \\
\text { Germany }\end{array}$} \\
\hline 0 & 83044 & 100.00 & 9.06 \\
\hline 3 & 78104 & 94.05 & 8.52 \\
\hline 10 & 69346 & 83.50 & 7.56 \\
\hline 23 & 50749 & 61.11 & 5.53 \\
\hline 31 & 46458 & 55.94 & 5.06 \\
\hline 60 & 27392 & 32.98 & 2.99 \\
\hline 72 & 21244 & 25.58 & 2.32 \\
\hline \multicolumn{4}{|c|}{$\begin{array}{c}\text { b = MI in pegmatite quartz from Ehrenfriedersdorf, Central-Erzgebirge, } \\
\text { Germany }\end{array}$} \\
\hline 0 & 230043 & 100.00 & 25.08 \\
\hline 18 & 184454 & 80.18 & 20.11 \\
\hline 26 & 168397 & 73.20 & 18.36 \\
\hline 32 & 157639 & 68.53 & 17.19 \\
\hline 45 & 129538 & 56.31 & 14.12 \\
\hline 51 & 125431 & 54.53 & 13.68 \\
\hline 61 & 108442 & 47.14 & 11.82 \\
\hline 72 & 95896 & 41.69 & 10.46 \\
\hline \multicolumn{4}{|c|}{$c=$ MI in an olivine crystal from Etna, Italy } \\
\hline 0 & 40333 & 100.00 & 4.40 \\
\hline 17 & 34092 & 84.53 & 3.72 \\
\hline 20 & 31361 & 77.76 & 3.42 \\
\hline 35 & 26729 & 66.27 & 2.91 \\
\hline 50 & 22698 & 56.28 & 2.48 \\
\hline 66 & 19375 & 48.04 & 2.11 \\
\hline 73 & 17671 & 43.81 & 1.93 \\
\hline 77 & 16752 & 41.54 & 1.83 \\
\hline 100 & 13096 & 32.47 & 1.43 \\
\hline 140 & 8965 & 22.23 & 0.98 \\
\hline 142 & 7826 & 19.40 & 0.85 \\
\hline \multicolumn{4}{|c|}{$\begin{array}{l}\text { Notes: Correlation of the integral intensity with the depth }-\mathbf{a}: I=10^{(4.915-0.00812 * D)} \text {, } \\
r^{2}=0.998 ; \mathbf{b}: I=10^{\left(5.362-0.00531^{*} \mathrm{D}\right)}, r^{2}=0.998 ; \mathbf{C}: I=10^{\left(4.602-0.00483^{*} \mathrm{D}\right)}, r^{2}=0.997 . \\
\text { * Depth (D) under the sample surface. } \\
+ \text { The integral intensity (I) at a depth of } 0 \mu \mathrm{m} \text { is equivalent to } 100 \% .\end{array}$} \\
\hline
\end{tabular}

surements we used an albite glass $\mathrm{AB} 83$ with $11.71 \mathrm{wt} \% \mathrm{H}_{2} \mathrm{O}_{\mathrm{T}}$, the reference spectra were obtained by focusing on the glass surface. The 7 data points from Table $2 a$ can be described by the following equation:

$$
\mathrm{I}=10^{(4.915-0.00812 * \mathrm{D})}, r^{2}=0.998
$$

(with $\mathrm{I}=$ integral intensity, $\mathrm{D}=$ depth of the inclusion in $\mu \mathrm{m}, r^{2}$ $=$ correlation coefficient). This yields a water concentration of $9.06 \pm 0.28 \mathrm{wt} \%$. This example shows that by reducing the depth of a MI in the host by step-wise grinding and polishing we can obtain enough information for the quantification of water from a single inclusion.

Table $2 \mathrm{~b}$ gives the results of the determination of total water concentration in a large MI in pegmatite quartz from Ehrenfriedersdorf, Central-Erzgebirge, Germany, homogenized at $600^{\circ} \mathrm{C}$, $1 \mathrm{kbar}$ for $20 \mathrm{~h}$. From the $1 \sigma$ scattering of the integral intensity of the MI data, and of the standard glass, the results give a mean of $25.1 \pm 1.1 \mathrm{wt} \% \mathrm{H}_{2} \mathrm{O}$.

Table $2 \mathrm{c}$ gives the results for the determination of total water concentration of 11 large (20-50 $\mu \mathrm{m}$ in diameter) MI in different depths in olivine from the Etna volcano, Italy. From the regression of the 11 data points we obtain a water concentration of $4.40 \pm 0.23 \mathrm{wt} \%$.

All three examples demonstrate that we can determine the water concentration in unexposed MI deep in the host. This is particularly useful in MI that are rich in water (example 2), since

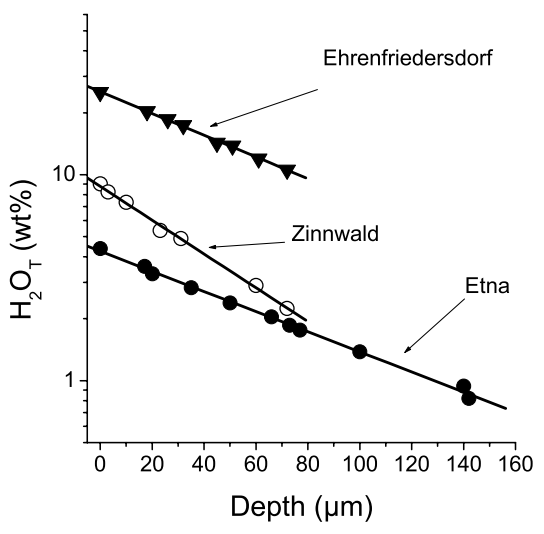

FIGURE 3. Calculated apparent water concentration $\mathrm{H}_{2} \mathrm{O}_{\mathrm{T}}$ (wt $\%$ ) vs. the inclusion depth (in $\mu \mathrm{m}$ ) for the three different examples. In all three cases the water content can be obtained by extrapolation to a depth of $0 \mu \mathrm{m}$.

if exposed the glass would immediately undergo irreversible changes (i.e., by diffusive loss to the atmosphere, among other mechanisms), and the primary water content would be indeterminable (see Ihinger et al. 1994).

In Figure 3, a plot of depth vs. $\log \left(\mathrm{H}_{2} \mathrm{O}\right.$ concentration), we obtain clear linear regressions. This suggests that it is possible to assess the water content adequately from a single inclusion by only two measurements. The larger the difference in distances to either surface, the more accurate is the determination. This technique could be used on a thin double-polished wafer by measuring from both sides (providing the inclusion is not exactly at the mid-point of the wafer), or by a two-stage polish and measure procedure when the sample is of suitable thickness.

As an example, considering the MI from Zinnwald, since the MI was located 72 and $10 \mu \mathrm{m}$, respectively, from both surfaces of the polished sample we obtain by the two-point equation for a line:

$$
\mathrm{I}=10^{(4.9239-0.008287 * \mathrm{D})}
$$

which gives a water concentration of $9.1 \pm 0.4 \mathrm{wt} \%$, using the integral intensity of the reference glass $( \pm 1 \sigma)$. In comparison, the estimate from 7 data points is $9.1 \pm 0.3 \mathrm{wt} \%$. Within the experimental limitations of this process the results are the same, and the second method would involve far fewer measurements and less sample preparation.

Given the non-destructive nature of this process, and the minimal sample preparation required, we consider the technique to have considerable advantages. It is also possible to use different inclusions at different depths (Etna case), although in this case it is necessary to assume that the MI all have similar $\mathrm{H}_{2} \mathrm{O}$ concentrations. This is not a problem if all of the MI are co-genetic, and there is no evidence of decrepitation or post-entrapment alteration of the inclusions. However, this method contains an internal check, because if the inclusions do not have similar $\mathrm{H}_{2} \mathrm{O}$ concentrations they will not lie on a single regression line (Fig. 3). Moreover, the degree of scatter will be proportional to the variability of $\mathrm{H}_{2} \mathrm{O}$ concentrations between inclusions. Should the 
inclusions in a sample not fit a single line, the methods for single inclusions can still be applied (examples 1 and 2).

The best results can be achieved if the MI is under the surface, thus largely avoiding the effects of preparation and other processes (e.g., water adsorption and diffusion). Furthermore, this method allows analysis of inclusions that are so water-rich that they cannot be exposed without causing irreversible changes. This method has the advantages of being non-destructive, cheaper than most other methods, and requiring less sample preparation, which is expensive and time-consuming. In the simplest case we can get good results from MI within double-polished wafers, simply measuring from both sides of the wafer. Furthermore, we stress that the integral intensity of the broad asymmetric $\mathrm{H}_{2} \mathrm{O}-\mathrm{OH}$ Raman band is directly proportional to the total water concentrations, and independent of the composition of the glass. The same is also valid for $\mathrm{D}_{2} \mathrm{O}$ in silicate glasses.

Because there is a linear correlation between the integral intensity and the $\mathrm{H}_{2} \mathrm{O}$ concentration, and since the regression curve goes through the zero point, it follows that only one standard is necessary for one determination. Furthermore, this means that the method can be applied within broad limits. It is only important that the sample and standard are measured under the same conditions, and that the water content should be roughly the same in standard and sample.

\section{ACKNOWLEDGMENTS}

We express our gratitude to H. Behrens and F. Holtz (University of Hannover), J.D. Webster (American Museum of Natural History, New York), H.R. Westrich (Sandia National Laboratories, Albuquerque, New Mexico), and R. Bodnar (Virginia Tech.) for providing glass standards for the calibration work. The authors also thank M. Leschik (University of Clausthal) and M. Wiedenbeck (GFZ Potsdam) for providing the reference glasses with $0.6-5.6 \mathrm{wt} \% \mathrm{D}_{2} \mathrm{O}$. The samples of olivine from Etna were provided by Massimo Pompilio (Pisa, Italy). The review by $\mathrm{M}$. Humphreys and of an anonymous reviewer greatly improved this paper.

\section{REFERENCES CITED}

Chabiron, A., Pironon, J., and Massare, D. (2004) Characterization of water in synthetic rhyolitic glasses and natural melt inclusions by Raman spectroscopy. Contributions to Mineralogy and Petrology, 146, 485-492.

Di Muro, A., Villemant, B., Montagnac, G., Scaillet, B., and Reynard, B. (2006) Quantification of water content and speciation in natural silicic glasses (phonolites, dacites, rhyolites) by confocal microRaman spectrometry. Geochimica et Cosmochimica Acta, in press.

Ihinger, P.D., Hervig, R.L., and McMillan, P.F. (1994) Analytical methods for volatiles in glasses. In M.-R. Carroll and J.R. Holloway, Eds., Volatiles in Magmas, 30, p. 67-121. Reviews in Mineralogy, Mineralogical Society of America, Chantilly, Virginia.

Leschik, M., Heide, G., Frischat, G.H., Behrens, H., Wiedenbeck, M., Wagner, N., Heide, K., Geißler, H., and Reinholz, U. (2004) Determination of $\mathrm{H}_{2} \mathrm{O}$ and $\mathrm{D}_{2} \mathrm{O}$ contents in rhyolitic glasses. Physics and Chemistry of Glasses, 45, 238-251.

Ohlhorst, S., Behrens, H., and Holtz, F (2001) Compositional dependence of mola absorptivities of near-infrared $\mathrm{OH}-$ and $\mathrm{H}_{2} \mathrm{O}$ bands in rhyolitic to basaltic glasses. Chemical Geology, 174, 5-20.

Thomas, R. (2000) Determination of water contents of granite melt inclusions by confocal laser Raman microprobe spectroscopy. American Mineralogist, $85,868-872$.

- - - (2002) Determination of water contents in melt inclusions by laser Raman spectroscopy. Workshop-Short course on volcanic systems, geochemical and geophysical monitoring-Melt inclusions: methods, applications and problems, p. 211-216. September $26-30^{\text {th }}$, Napoli, Italy.

Thomas, R., Webster, J.D., and Heinrich, W. (2000) Melt inclusions in pegmatite quartz: complete miscibility between silicate melts and hydrous fluids at low pressure. Contributions to Mineralogy and Petrology, 139, 394-401.

Thomas, R., Förster, H.-J., and Heinrich, W. (2003) The behaviour of boron in a peraluminous granite-pegmatite system and associated hydrothermal solutions: a melt and fluid inclusion study. Contributions to Mineralogy and Petrology, $144,457-472$.

Thomas, R., Förster, H.-J., Rickers, K., and Webster, J. (2005) Formation of extremely F-rich hydrous melt fractions and hydrothermal fluids during differentiation of highly evolved tin-granite magmas: a melt/fluid inclusion study. Contributions to Mineralogy and Petrology, 148, 582-641.

Webster, J.D., Kinzler, R.J., and Mathez, E.A. (1999) Chloride and water solubility in basalt and andesite melts and implications for magmatic degassing. Geochimica et Cosmochimica Acta, 63, 729-738.

MANUSCRIPT RECEIVED SEPTEMBER 28, 2005

MANUSCRIPT ACCEPTED NOVEMBER 15, 2005

MANUSCRIPT HANDLED BY BRYAN CHAKOUMAKOS 